\title{
Social status and life satisfaction in context: A comparison between Sweden and the USA
}

\author{
Filip Fors Connolly · Ingemar Johansson Sevä
}

\begin{abstract}
Previous research has shown that social status is an important predictor of life satisfaction (LS). However, researchers have largely focused on the United States, which raises questions about the extent to which the cultural context moderates the relationship between social status and LS. In this paper, we argue that the dominant cultural orientations in society most likely influence the strength of the relationship between social status and LS. Cultural orientations emphasizing competition, achievement and assertiveness should increase the positive influence of social status on LS, while cultural emphases on cooperation, equality and humility instead weakens the effect of status. We therefore analyze the social status-LS relationship in two distinctly different cultural contexts, i.e., Sweden and the United States. Based on theories about national differences in cultural value orientations, we argue that social status should be of more importance in the US compared to in Sweden, since the dominant values and ideals emphasize hierarchy, mastery and masculinity, while the Swedish culture represents an opposite pole by emphasizing egalitarianism, harmony, and femininity. We formulate a number of hypotheses and use survey data to examine the extent to which both social status attainment and social status seeking are related to LS in both countries. The results show that socioeconomic status (income) and sociometric status (perceived respect and admiration in everyday life) have a stronger influence on LS in the US compared to in Sweden. Further, the findings show that social status seeking (low honesty-humility) has a positive relationship to LS in the US, but is negatively related in Sweden. The results also show that gender differences in the relationship between social status and LS are more pronounced in the US compared to in Sweden. We conclude that both the attainment and pursuit of social status are more important for LS in the American cultural context compared to in the Swedish, especially among men. These findings are in line with our expectations, based on the opposing cultural orientations in Sweden and the US. The study contributes to the literature on the relationship between social status and LS, but also to the more general literature on the moderating influence of culture on the predictors of LS.
\end{abstract}

Keywords: subjective wellbeing, life satisfaction, social status, cultural orientations, socioeconomic status, sociometric status, status seeking, Sweden, USA

\section{Introduction}

Life satisfaction (LS) has become one of the most important benchmarks when measuring the quality of life across countries. Both the OECD (2011) and the United Nations (Helliwell, Huang \& Wang, 2017) promote LS as an important welfare indicator complementing traditional measures such as GDP and life expectancy when assessing levels of wellbeing across countries. Since LS is such a central component of individuals' overall wellbeing and quality of life, much research has examined its determinants (for a review see e.g., Dolan, Peasgood, \& White, 2008; 
Veenhoven, 2015). Recently, studies have found that social status, and particularly an individual's position on the "local ladder" (i.e., respect and admiration from peers), have a strong impact on LS (Anderson, Kraus, Galinsky, \& Keltner, 2012). This finding is not surprising because psychologists have previously proposed that social status constitutes a fundamental human motive (Hogan \& Hogan, 1991; Anderson, Hildreth, \& Howland, 2015). Moreover, previous research has shown that social status and adjacent concepts such as occupational prestige (Treiman, 2013) predict various other outcomes related to wellbeing, such as health, self-esteem, and job satisfaction (Smith 2004; Fujishiro, Xu, \& Gong, 2010; Weaver, 1977).

However, since present evidence about the relationship between social status and LS mostly comes from studies conducted in the US, it is unclear whether cultural context influences the relationship between social status and LS. Indeed, previous research suggests that cultural norms can affect certain correlates of LS within countries. Oishi, Diener, Lucas, and Suh (1999) identify a systematic relationship between salient cultural values that differs between countries as well as geographical regions and standards for life satisfaction, judgments, and emotional experiences. For example, perceptions of freedom predict life satisfaction more strongly in individualist countries compared to in collectivist countries, supporting the idea that individual freedom is a more salient value in individualistic cultures (Oishi et al., 1999). Furthermore, Kwan, Bond and Singelis (1997) found that "relationship harmony" was a more important predictor of life satisfaction in Hong Kong compared to in the United States, suggesting that harmonious relationships are more highly valued in the Chinese culture compared to in the American culture. Findings like these suggest that the relationship between contextual factors and LS is complex, and that contextual characteristics most likely affect the relationship between many individuallevel predictors and LS.

The aim of this study is to increase the knowledge about cross-national differences in the relationship between social status and LS, by focusing on the potential impact of cultural norms on this relationship. By using unique survey data from Sweden and the US, we can examine the social status-LS relationship in two distinctly different cultural contexts. While competition, selfachievement and assertiveness characterize American culture, the Swedish culture is more egalitarian and emphasizes ideals such as cooperation and humility (Hofstede, 2001; Schwartz, 2006). We argue that these differences in cultural orientations most likely affect the significance of social status in society, which, in turn, might have important consequences for the relationship between social status and LS. On a more general level, this study also attempts to provide a more comprehensive analysis of the relationship between social status and LS by examining how the LS of individuals in the US and Sweden are related to not only social status attainment, but also social status seeking. Finally, since the main findings from previous research regarding gender differences in the importance of social status for LS are somewhat mixed (Buss, 1999; Hays, 2013), we also analyze to what extent such differences exist, and whether cultural contexts can contribute to the understanding of differences between women and men in terms of the relationship between social status and LS.

\subsection{LS and social status attainment}

Most scholars make a distinction between two different components of subjective wellbeing (SWB): life satisfaction and affective wellbeing (Diener, 1984; Kahneman \& Deaton, 2010). Whereas life satisfaction concerns individuals' evaluations of their lives, affective wellbeing reflects the balance between pleasant and unpleasant affect in people's lives (Diener, 1984; Brülde, 2007). Comparative studies of LS have found large differences between countries, typically finding the highest levels of LS in countries characterized by high levels of GDP per 
capita, life expectancy and social capital (Helliwell, Huang, \& Wang, 2017). Within countries, previous research suggests that LS is higher among extraverted and emotionally stable individuals, those with high income, and people with good health; and lower among the unemployed and people who are lonely (Blanchflower, 2009; Mellor, Stokes, Firth, Hayashi, \& Cummins, 2008). However, as we will elaborate below, social status is also an important predictor of LS.

Anderson et al. (2015, p. 575) define social status as "the respect, admiration, and voluntary deference individuals are afforded by others," meaning that others hold high-status individuals in high regard and voluntarily comply with high-status individuals' needs and desires without the need for threat or coercion. It should be noted that social status can operate at different levels. On one hand, it can refer to people's global status position in society at large (Adler et al., 1994; Anderson et al., 2012). Researchers often capture this status dimension by using the term "socioeconomic status" (Adler et al., 1994). On the other hand, it can refer to the more local level in terms of people's status among peers and the respect and admiration they experience in their everyday interactions (Anderson et al., 2012). Researchers often label this form of social status as "sociometric status." Previous studies have shown that both socioeconomic status and sociometric status predict subjective wellbeing. For example, people who score high in these two status-dimensions tend to be more satisfied with their lives and experience more positive emotions and fewer negative emotions compared to people who score low on social status (Layard, Clark, Cornaglia, Powdthavee \& Vernoit, 2014; Anderson et al., 2012). Furthermore, research suggests that sociometric status has a stronger relationship with SWB compared to socioeconomic status, and that sociometric status predicts SWB when using both experimental and longitudinal research designs (Anderson et al., 2012). The fact that high-status individuals experience greater control over their social environment and increased levels of belonging and acceptance may explain these results (Anderson et al., 2012). However, it is important to note that the evidence of a strong connection between social status and SWB mostly comes from studies conducted in the United States.

\subsection{Social status seeking and LS}

Not only is the attainment of social status relevant for LS, the pursuit of social status might also matter for the extent to which individuals experience wellbeing. The pursuit of social status is understood both in terms of how individuals value abstract goals such as power and achievement (Schwartz, 1994), as well as more enduring personality dispositions, i.e., "what people are like" in terms of their habitual behaviors, feelings, and thoughts (Costa \& McCrae, 1990) in relation to social status. Although status seeking is not clearly captured in dominant personality trait models such as the Five-Factor Model, it is central in the recently proposed HEXACO-model under a trait named honesty-humility (Lee \& Ashton, 2004, 2013). People with low scores on the honesty-humility dimension want to enjoy and display wealth and privilege and actively pursue superior social status. Conversely, individuals who score high in this dimension are not overly motivated by social-status considerations and view themselves as ordinary people without any entitlement to elevated social status (Lee \& Ashton, 2013). In a study connecting honesty-humility to socio-political orientations in the US, Lee, Ashton, Ogunfowora, Bourdage, and Shin (2010) found that people low in honesty-humility prefer a more hierarchical society in contrast to people high in honesty-humility, who prefer a more egalitarian social order. Using data from a Swedish sample, Kajonius and Dåderman (2014) found a similar pattern, showing that people with high scores on honesty-humility strongly favor a more equal distribution of resources within society. We argue that these results indicate that status-seeking 
tendencies (low honesty-humility) will be more beneficial for wellbeing in a hierarchical context compared to in an egalitarian context. As a consequence, individuals low in honesty-humility would be more satisfied with their life if they lived in a more hierarchical society, whereas the opposite would hold for individuals high in honesty-humility.

A few previous studies examine the influence of honesty-humility on LS. Pollock, Noser, Holden, and Zeigler-Hill (2016) found a weak negative (non-significant) relationship between honesty-humility and life satisfaction in a small US sample $(\mathrm{r}=-.03)$. Other related studies from the US have shown that people who value financial success and material resources (i.e., values/attitudes related to status seeking) tend to have somewhat lower levels of LS compared to people who put less emphasis on these values (Kasser \& Ryan, 1993). Given the fact that few studies generally exist on the topic, and that researchers have not conducted studies on the relationship between honesty-humility and LS in Sweden (to our knowledge), further investigations about the general relationship between social status seeking and LS, as well as whether cultural contexts moderate this relationship, are warranted.

\subsection{The cultural contexts of Sweden and the US}

Turning to the issue of whether cultural context influences the relationship between social status and LS, we now elaborate on why social status attainment and social status seeking might be of greater importance for individuals in certain cultural contexts than in others. National cultures are the shared values, beliefs, and norms that are common for the majority of individuals within a nation. These cultural orientations thus convey common preferences and ideals regarding what is viewed as good and desirable in society (Schwartz, 2006). In his seminal work on cross-cultural differences, Hofstede (1980, 2001) describes national culture as the value system and "mental programming" shared by the majority of individuals in a specific country.

Scholars have proposed that national cultures originate from the fact that societies face certain basic problems that they need to address, but that there are different ways to solve these problems. Hofstede (1980, 2001) identifies five (later six) cultural dimensions, representing collective preferences for one state of affairs over another. Country scores on these dimensions thus distinguish countries from each other in terms of the common values and the promotion of certain societal norms when addressing a specific societal problem. Similarly, Schwartz (2006) defines culture and cultural differences by referring to the underlying value orientations influencing social structures and relations. In line with Hofstede, Schwartz argues that these value orientations "evolve as societies confront basic issues or problems in regulating human activity" (Schwartz, 2006, p. 140). According to Schwartz, cultures differ on three bipolar dimensions, establishing seven interdependent cultural value orientations, ordered in a circle. The interdependent nature of these cultural dimensions suggests that if a specific culture emphasizes one polar value orientation, it typically de-emphasizes the cultural values of the opposing pole.

The notion that national cultures (in terms of basic value orientations) exist has received empirical support. For example, Minkov and Hofstede (2012) found that, for a majority of the 28 countries studied, the value orientations of 299 in-country regions cluster along national lines rather than across borders. While emphasizing that different sets of values tend to distinguish between national cultures to a varying extent across different parts of the world, they nevertheless conclude: "It proves that national cultures can be distinguished if an appropriate selection of cultural indicators is used" (Minkov \& Hofstede, 2012, p. 153). Moreover, the fact that somewhat different conceptualizations of cultural dimensions tend to correlate highly, despite differences in measurements, indicators, and samples, suggests that there seem to be 
meaningful cultural differences across countries. Schwartz (2006) provides evidence in support of such similarities between various cultural theories by finding a considerable overlap between different conceptualizations of cultural dimensions.

In this study, we argue that the cultures of Sweden and the US differ in significant ways regarding their dominant values and societal norms. Further, we argue that these differences should have substantial implications for the relationship between social status and LS. Below, we discuss why the importance of social status generally should be more salient in the US culture compared to in the Swedish, and, consequently why, the social status-LS relationship should be stronger in the US compared to in Sweden.

As discussed previously, a number of different theories about cultural orientations provide similar pictures of the national cultures of Sweden and the US (see e.g., Hofstede 2001; Schwartz 2006). One of Hofstede's cultural dimensions stands out as highly relevant in relation to the interplay between social status and LS, as well as in relation to potential gender differences in this link. Hofstede (2001) refers to this dimension as masculinity (versus femininity), capturing a fundamental dilemma of human societies regarding the relative strength of nurturance interests (social) and assertiveness interests (ego). Hofstede labels the assertive pole "masculine" and the modest pole "feminine," referring to the distribution of emotional roles (learned styles of interpersonal interaction) between men and women in society, i.e., the dominant gender roles. According to Hofstede, this dimension captures the degree to which social gender roles are clearly distinct in society, meaning that men ought to be assertive and focus on achievement while women should be modest and focus on cooperation. While countries scoring high on the masculinity dimension have more pronounced differences, in feminine countries, gender roles instead tend to overlap, i.e., both men and women are supposed to be modest and more oriented towards cooperation. This dimension thus captures the extent to which assertiveness, competition, and wealth are valued as societal ideals rather than humility, cooperation, and modesty. According to Hofstede, the difference between Sweden and the US on the masculinity dimension is substantial. Sweden's score places the country as the most feminine among all countries surveyed, while the US score ranks well above the average among the countries at the masculine end of the scale (Hofstede, 2001). Consequently, while wealth and recognition are measures of achievement in the US, social relationships and quality of life tend to be the sources of achievement in Sweden. These cultural orientations also suggest that gender differences should be more pronounced in the US than in Sweden.

Based on another common problem for societies, namely, ensuring that people behave in productive ways that preserve society and the social structure, Schwartz (2006) derives an egalitarianism/hierarchy dimension. At one end, egalitarian cultures emphasize values such as equality, social justice, and cooperation to uphold the social fabric of society. Hierarchy cultures, at the other pole, instead make use of hierarchical systems of ascribed roles to ensure that people behave responsibly and in a productive manner. Hierarchy cultures define the unequal distribution of power, roles, and resources as legitimate and even desirable, in order to promote stable social relations in society. As a result, values such as social power, authority and wealth are important in hierarchical cultures.

Adjacent to egalitarianism and hierarchy lies another cultural dimension, with the two opposing value orientations of harmony and mastery. Schwartz (2006) argues that the harmonymastery dimension is derived from yet another common problem that societies face, namely, how people manage their relations to the natural and social world. At the harmony pole, the cultural orientations emphasize peace and unity with nature and consequently encourage people to understand and appreciate the world as it is rather than try to change or exploit it. Conversely, 
cultures scoring high on the mastery value orientation encourage active self-assertion to master, direct, and change the natural and social environment in order to achieve personal or group goals.

While the cultural orientations associated with both egalitarianism and harmony stimulate equality, humility and cooperative regulation of interdependence, the contrasting cultural poles of hierarchy and mastery justify inequality, competition, and the differential distribution of resources associated with competition. This suggests that people are more likely to view assertiveness and competition as something good if they live in a country where the cultural value orientations emphasize hierarchy and mastery, as opposed to egalitarianism and harmony.

According to Schwartz (2006), the cultures of Sweden and the US differ notably regarding the emphasis on these cultural orientations, suggesting that each culture promotes different societal norms and ideals. While the Swedish culture, being part of the broader group of Western European countries, puts very low emphasis on hierarchy and mastery in favor of the opposing values of egalitarianism and harmony, the US culture promotes ideals and norms in line with the cultural orientations of hierarchy and mastery. Hence, the Swedish culture encourages people to be modest about their achievements, paying attention to the fictitious "Jante law" that stipulates that you should not stand out from the crowd. The US culture instead encourages "an assertive, pragmatic, entrepreneurial, and even exploitative orientation to the social and natural environment" (Schwartz, 2006, p. 158). This means that Americans should be more prone to display and talk freely about their "successes" and achievements in life. Some even claim that being successful per se is not the great motivator in American society, but rather being able to show one's success (Hofstede, 2001). In line with this, studies also show that Americans generally work longer hours than Swedes (Ohanian \& Raffo, 2012), and that their work orientations indicate that they "live to work" (Okulicz-Kozaryn, 2011). Observed correlations between social attitudes and cultural values further corroborate these findings. For example, Schwartz (2006) shows that the proportion of the general public stating that "hard work" is an especially desirable quality for children to learn is positively correlated with hierarchy and mastery orientations. Further, it is more common for individuals in these cultural contexts to agree that "competition is good" (Schwartz, 2006). These findings suggest that Americans, in comparison with Swedes, tend to work harder to obtain monetary rewards, and as a consequence attain higher social status based on how successful they are. Finally, regarding potential gender differences, Schwartz's findings demonstrate that cultures emphasizing egalitarianism and harmony tend to promote women's equality, for example, in terms of education, health, and employment. This, in turn, suggests that gender differences in the relationship between social status and LS should be more salient in the US compared to in Sweden.

The differences in cultural orientations between Sweden and the US are, of course, also related to the actual distribution of material resources. Other perspectives therefore further contribute to the understanding of the differences between the Swedish and the American societies by highlighting that there are substantial differences, for example, in income inequality and welfare state arrangements. Many approaches put an emphasis on institutional structures as intervening factors affecting the distribution of material resources and consequently class and gender inequality (e.g., Korpi, 2000). Because it is difficult to design institutions and implement social policies that are not in line with the prevailing norms and ideals in society, the design of institutions and the outcomes associated with them are inevitably linked to societal values and cultural orientations. Political institutions thereby provide additional guidelines for how individuals think, act, and behave in relation to inequality and competition. For example, Svallfors (2006) finds that while $17 \%$ of Americans agree that it should be the government's 
responsibility to reduce income differences between the rich and the poor, in Sweden the corresponding share is $43 \%$. The reluctance to reduce income differences in the US may be explained by the fact that Americans to a large extent believe that individual effort determines their social status and that differences in social status are legitimate (Alesina \& Angeletos, 2003). We argue that the extent to which status differences are viewed as legitimate contributes in determining the strength of the relationship between social status and wellbeing.

\subsection{Hypotheses}

Based on the differences in cultural orientations and institutional contexts between the US and Sweden, we formulate four hypotheses regarding the relationship between LS and the attainment and pursuit of social status. First, we expect that social status attainment in general, both in terms of socioeconomic and sociometric status, should be of more importance for the LS of individuals in the US compared to in Sweden, resulting in the following hypotheses:

Hypothesis 1A: Socioeconomic status is more strongly associated with LS in the US compared to in Sweden;

Hypothesis 1B: Sociometric status is more strongly associated with LS in the US compared to in Sweden.

Further, we anticipate a slightly positive relationship between social status seeking and life satisfaction in the US, since American cultural values emphasize competition and assertiveness, even though a previous study found no association between honesty-humility and LS in the US (Pollock et al., 2016). However, this study analyzed only a small non-representative sample ( $\mathrm{n}=$ 153), which makes further investigations into the association between honesty-humility and life satisfaction in the US highly warranted. Conversely, given the importance of modesty and humility in Swedish culture, we anticipate that status-seeking behaviors come into conflict with the social norms and are perhaps even penalized, and we therefore expect to find a negative relationship between social status seeking and LS in Sweden. Hence, we formulate the following hypothesis:

Hypothesis 2: Social status seeking is negatively associated with LS in Sweden, while positively associated with LS in the US.

Finally, regarding potential gender differences in the relationships between social status attainment and LS, as well as social status seeking and LS, we expect that such differences should be smaller in Sweden compared to in the US, depending on differences in cultural orientations relating to masculinity, hierarchy, and mastery, but also depending on the level of gender equality, thus:

Hypothesis 3: Social status and status seeking is more strongly associated with LS for men compared to women in the US, while such gender differences are smaller in Sweden.

\section{Method}

\subsection{Data}

We used Qualtrics (http://www.qualtrics.com) web-survey panels in the US and Sweden to recruit respondents for this study. Three different attention checks were used in the survey to filter out respondents who did not fill out the questionnaire carefully. The data collection stopped 
when Qualtrics recorded 1,260 completed survey responses in each country. The questionnaire was provided in English for the American sample and in Swedish for the Swedish sample. Previous studies comparing survey samples provided by commercial platforms such as Qualtrics with population data show that such samples tend to be fairly representative (Heen, Lieberman and Miethe, 2014).

\subsection{Measures}

We measured LS using a single-item question on life satisfaction taken from the European Social Survey. The question reads as follows: "All things considered, how satisfied are you with your life as a whole nowadays?" To answer the question, respondents used a response scale ranging from 0 to 6 with endpoints labelled "extremely dissatisfied" and "extremely satisfied." Previous research suggests that this single-item life satisfaction question is a reliable measure of life satisfaction, both within and between countries (Cheung \& Lucas, 2014; Fors \& Kulin, 2016).

To measure socioeconomic status, we used respondents' household income as a proxy variable. Household income has been widely used in previous studies to measure socioeconomic status (see, for example, Adler et al., 1994). Aside from income, indicators of education and occupation are also widely used measures of socioeconomic status. However, we chose income instead of education and occupation, since previous research suggests that income is a more robust determinant of LS (Argyle, 2003). We measured annual household net income using five country-specific income categories. The US questionnaire used the following categories: 1: $\$ 0$ to $\$ 24,999,2: \$ 25,000$ to $\$ 49,999,3: \$ 50,000$ to $\$ 74,9994$ : $\$ 75,000$ to $\$ 99,999,5: \$ 100,000$ or more. The Swedish questionnaire used currency conversions to Swedish SEK for each income category, with figures rounded off to the nearest thousandth.

To capture sociometric status, we used three items adapted from a study by Anderson et al. (2012). Respondents indicated to what extent they agreed or disagreed with the following statements: "I have a high level of respect in others' eyes," "I have high social standing," and "Others look up to me." We rated agreement to these statements on a scale from 1 ("Strongly disagree") to 5 ("Strongly agree") and averaged the ratings of the three statements into an index. Cronbach's alpha for the index was .81 for US men, .76 for US women, .79 for Swedish men and .77 for Swedish women, suggesting an acceptable internal reliability in both countries and for both men and women.

We measured social status seeking using all four items from the honesty-humility dimension of the Mini-IPIP6 personality scale (Sibley et al., 2011). The questionnaire asked respondents to indicate to what extent the following statements reflected their personality: "Feel entitled to more of everything," "Deserve more things in life," "Would get a lot of pleasure from owning expensive luxury goods," and "Would like to be seen driving around in a very expensive car." We recorded answers on a 7-point scale with endpoints labelled "Very inaccurate" (1) to "Very accurate" (7) and averaged the ratings of the four statements into an index. Cronbach's alpha for the index was .85 for US men, .81 for US women, .71 for Swedish men and .67 for Swedish women. Although the alpha values were somewhat low in Sweden, we believe that they are acceptable, taking into consideration that there were only four items included in the measure.

In order to control for other relevant individual-level characteristics that affect life satisfaction, we measured the Big Five personality traits using the same Mini-IPIP6 personality scale (Sibley et al., 2011) described above. All of these five traits have been connected to life satisfaction in previous research (Steel, Schmidt \& Shultz, 2008). We measured each trait using four statements averaged into an index. Cronbach's alpha for the extraversion measure was .71 in the US and .80 in Sweden, .75 (US) and .68 (SWE) for agreeableness, .59 (US) and .72 (SWE) for 
conscientiousness, .57 (US) and 77 (SWE) for neuroticism, and finally .68 (US) and .69 (SWE) for openness.

We also included age as a control variable (six categories), since this variable has been connected to life satisfaction in some previous studies (Blanchflower \& Oswald, 2008). Finally, to control for respondents' material living conditions, which affect life satisfaction (Sacks, Stevenson \& Wolfers, 2012), we included a measure of financial satisfaction when examining the relationship between socioeconomic status and LS. Respondents indicated their satisfaction with their "financial situation" on a 7-point bipolar scale ranging from 0 ("Extremely dissatisfied") to 6 ("Extremely satisfied").

\section{Results}

Table 1 below shows the demographic and personality structure of the samples in terms of gender, age, education, relationship status, and the Big Five personality traits. The demographic structure of the two samples does not differ in relation to gender $(\chi 2=0.057 ; p=.811)$ and age $(\chi 2=2.843 ; p=.724)$. The Swedish sample reported significantly lower income $(\chi 2=148.566 ; p=$ $.000)$, fewer education years $(\chi 2=107.423 ; p=.000)$ and a larger portion of this sample reported themselves as single $(\chi 2=6.596 ; p=.037)$. Regarding the Big Five personality traits (measured by the Mini-IPIP) the American sample scored higher on extraversion $(t=2.374 ; p=.018$ ), conscientiousness $(t=6.120 ; p=.000)$, and openness $(t=3.531 ; p=.000)$ but lower on neuroticism $(t=-3.056 ; p=.002)$. We found no significant differences regarding agreeableness $(t=1.512 ; p=$ .131). Since population statistics for most of the variables above are not available, and therefore unknown, we include age and the Big Five traits as controls in our analysis.

In Table 2 below, we report descriptive statistics and correlations for our key variables: life satisfaction, socioeconomic status, sociometric status, and status-seeking personality (see Appendix Table 1 for correlations between all variables used in the analysis). Regarding our outcome variable, we find that the level of life satisfaction is higher in the US sample compared to the Swedish sample $(t=6.530 ; p=.000)$. Similarly, the descriptive statistics for the two measures capturing social status attainment indicate that levels are higher in the American sample, both in terms of socioeconomic status $(t=9.168 ; p=.000)$ and sociometric status $(t=11.230 ; p=.000)$. The table also shows that the American sample scored higher on the measure capturing a statusseeking personality $(t=8.002 ; p=.000)$. We also note that, across all measures, the standard deviation is higher in the US sample compared to the Swedish sample. Because previous studies have shown that US society is more unequal compared to Sweden in relation to both income (Fritzell, 1999) and health (Doorslaer et al., 1997), this finding is expected. 
Table 1. Descriptive statistics for sociodemographic variables and personality traits in Sweden and USA

\begin{tabular}{|c|c|c|c|c|c|}
\hline & & \multicolumn{2}{|c|}{ Sweden } & \multicolumn{2}{|l|}{ USA } \\
\hline & & $\mathrm{n}$ & $\%$ & $\mathrm{n}$ & $\%$ \\
\hline \multirow[t]{6}{*}{ Age } & $18-24$ & 115 & 9.1 & 138 & 11.0 \\
\hline & $25-34$ & 231 & 18.3 & 234 & 18.6 \\
\hline & $35-44$ & 228 & 18.1 & 220 & 17.5 \\
\hline & $45-54$ & 239 & 19.0 & 224 & 17.8 \\
\hline & $55-64$ & 216 & 17.1 & 210 & 16.7 \\
\hline & 65 or older & 231 & 18.3 & 234 & 18.6 \\
\hline \multirow[t]{2}{*}{ Gender } & Male & 589 & 46.7 & 595 & 47.2 \\
\hline & Female & 671 & 53.3 & 665 & 52.8 \\
\hline \multirow[t]{6}{*}{ Number of education years } & $0-5$ & 25 & 2.0 & 66 & 5.2 \\
\hline & $6-10$ & 128 & 10.2 & 67 & 5.3 \\
\hline & $11-15$ & 670 & 53.2 & 503 & 39.9 \\
\hline & $16-20$ & 369 & 29.3 & 475 & 37.7 \\
\hline & $21-25$ & 57 & 4.5 & 109 & 8.7 \\
\hline & 26 or more & 11 & 0.9 & 40 & 3.2 \\
\hline \multirow[t]{5}{*}{ Household income (net) } & $\$ 0$ to $\$ 24,999$ & 261 & 20.7 & 227 & 18.0 \\
\hline & $\$ 25,000$ to $\$ 49,999$ & 390 & 31.0 & 287 & 22.8 \\
\hline & $\$ 50,000$ to $\$ 74,999$ & 326 & 25.9 & 245 & 19.5 \\
\hline & $\$ 75,000$ to $\$ 99,999$ & 184 & 14.6 & 177 & 14.1 \\
\hline & $\$ 100,000$ or more & 99 & 7.9 & 323 & 25.7 \\
\hline \multirow[t]{5}{*}{ Relationship status } & Cohabiting & 753 & 59.8 & 815 & 64.7 \\
\hline & Has partner but not & & & & \\
\hline & cohabiting & 96 & 7.6 & 88 & 7.0 \\
\hline & Single (no partner) & 411 & 32.6 & 357 & 28.3 \\
\hline & & $\mathrm{n}$ & mean & $\mathrm{n}$ & mean \\
\hline \multirow[t]{5}{*}{ Big Five personality traits } & Agreeableness & 1260 & 5.08 & 1260 & 5.15 \\
\hline & Conscientiousness & 1260 & 4.88 & 1260 & 5.15 \\
\hline & Extraversion & 1260 & 3.75 & 1260 & 3.88 \\
\hline & Neuroticism & 1260 & 3.71 & 1260 & 3.57 \\
\hline & Openness & 1260 & 4.85 & 1260 & 5.02 \\
\hline
\end{tabular}

We find that socioeconomic status and sociometric status are moderately correlated, suggesting that people with high income also tend to report higher levels of respect and admiration in their everyday life. However, since the correlation between these types of social status is far from perfect, the data also support the notion that socioeconomic status and sociometric status are two distinct (although correlated) phenomena. As expected, the data show a positive relationship between life satisfaction and both socioeconomic status and sociometric status. Although status 
seeking is positively correlated with both income and sociometric status, we find no correlation in the pooled sample between status seeking and LS.

Table 2. Descriptive statistics and bivariate correlations for key variables

\begin{tabular}{lccccllll}
\hline & \multicolumn{2}{c}{ Sweden } & \multicolumn{2}{c}{ USA } & & & \\
mean & s.d. & mean & s.d. & $\begin{array}{l}\text { Life } \\
\text { satisfaction }\end{array}$ & $\begin{array}{l}\text { Household } \\
\text { income }\end{array}$ & $\begin{array}{l}\text { Sociometric } \\
\text { status }\end{array}$ & $\begin{array}{l}\text { Status } \\
\text { seeking }\end{array}$ \\
\hline $\begin{array}{l}\text { Life } \\
\begin{array}{l}\text { Satisfaction } \\
\text { Household }\end{array}\end{array}$ & 3.76 & 1.37 & 4.13 & 1.49 & 1 & & & \\
$\begin{array}{l}\text { income } \\
\begin{array}{l}\text { Sociometric } \\
\text { status }\end{array}\end{array}$ & 2.58 & 1.19 & 3.07 & 1.45 & 0.32 & 1 & & \\
$\begin{array}{l}\text { Status } \\
\text { seeking }\end{array}$ & 3.12 & 1.14 & 3.56 & 1.60 & 0.01 & 0.21 & 0.31 & 1 \\
\hline
\end{tabular}

Note: All mean differences between Sweden and USA are statistically significant at the .001-level (independent samples T-test). All correlations, except the correlation between status seeking and life satisfaction, are statistically significant at the .001-level.

\subsection{Socioeconomic status, sociometric status and life satisfaction}

We now begin our analysis by investigating the relationship between social status attainment and life satisfaction in Sweden and the US, thereby testing Hypotheses 1A-B. These hypotheses suggest that income (H1A) and sociometric status (H1B) are more strongly related to LS in the US compared to in Sweden. We tested a series of multiple regression models, each with country as the moderating factor. We performed the moderation analysis using Model 1 in the SPSS process macro (Hayes, 2013), with 95\% bias corrected confidence intervals and we calculated statistical significance using 5,000 bootstrapping replications.

In Model 1, presented in Table 3 below, life satisfaction constitutes the dependent variable and socioeconomic status (total annual household income) is the main independent variable. As expected, the results show that there is a positive association in general between household income and life satisfaction. However, when adding the interaction term between country and income in Model 2, we find that the effect of income on LS is moderated by country. The statistically significant interaction effect (Model 2) indicates that income has a stronger impact on LS in the US compared to in Sweden. In Model 3, we include the control variable measuring respondents' satisfaction with their financial situation. We consider this variable to be a proxy for the respondents' material living conditions, and by including it, our intention is to ensure that the relationship between income and LS found in Model 2 captures social status in society at large rather than differences in material living standards and financial stress (cf Joo \& Grable, 2004). The results in Model 3 show that the positive association between socioeconomic status (household income) and life satisfaction remains when taking the respondents' financial situations into account.

For illustrative purposes, the interaction between socioeconomic status and country is presented graphically in Figure 1 below. The y-axis represents predicted values on the life satisfaction scale for the mean income and one standard deviation below and above the mean ( $x-$ axis). Here we find that the difference in LS between the low- and high-income categories is 0.74 in the US and 0.42 in Sweden. The figure clearly illustrates that the relationship between 
socioeconomic status and life satisfaction is stronger in the US compared to in Sweden, thereby indicating that country moderates the relationship between socioeconomic status and LS.

Table 3. The relationship between socioeconomic status and life satisfaction

\begin{tabular}{llll}
\hline & Model 1 & Model 2 & Model 3 \\
\hline Country (USA = 1, Sweden = ) & $0.16^{* *}$ & -0.17 & -0.06 \\
& $(0.05)$ & $(0.11)$ & $(0.10)$ \\
Income & $0.23^{* *}$ & $0.16^{* *}$ & -0.02 \\
& $(0.02)$ & $(0.03)$ & $(0.03)$ \\
Income X Country & & & \\
& & $0.12^{* *}$ & $0.08^{* *}$ \\
Satisfaction with financial situation & & $(0.04)$ & $(0.03)$ \\
& & & $0.36^{* *}$ \\
& & & $(0.01)$ \\
Constant & & & \\
& & & \\
Individual characteristic controls & $4.39^{* *}$ & $4.52^{* *}$ & $3.50^{* *}$ \\
Observations & $(0.21)$ & $(0.21)$ & $(0.21)$ \\
\hline
\end{tabular}

Note: ${ }^{*} \mathrm{p}<0.05,{ }^{* *} \mathrm{p}<0.01$. Cell entries represent unstandardized regression coefficients.

Figure 1. Interaction effect of socioeconomic status and country on life satisfaction

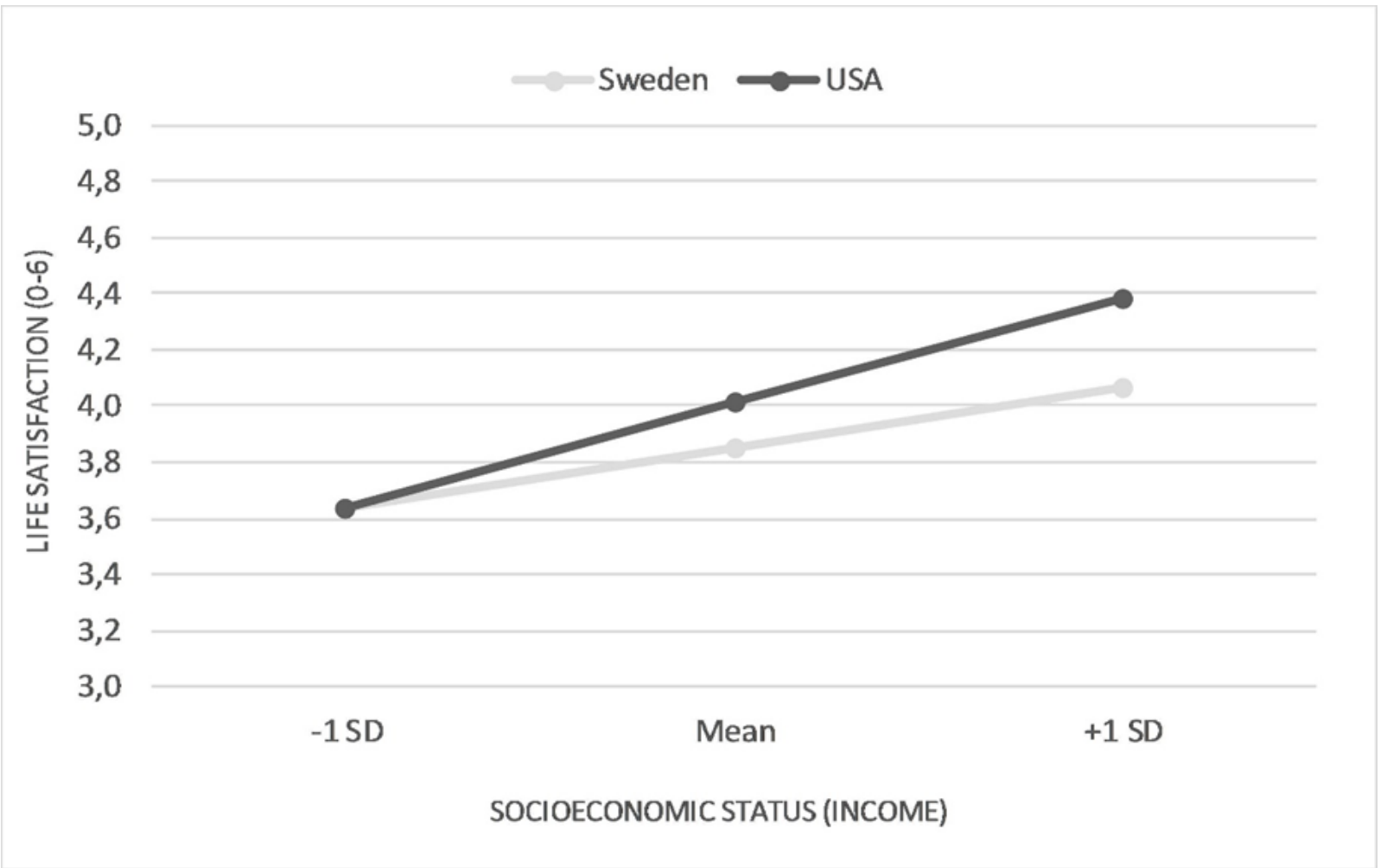

Note: Conditional effects and standard errors: USA: .28 (.024); Sweden: .16 (.028). 
Turning to the next aspect of social status attainment, we present the relationship between sociometric status and LS in Table 4. To begin with, we find a positive relationship between sociometric status and LS in the pooled sample (Model 1). Similarly to the results for socioeconomic status and LS, we find that the interaction term between sociometric status and country (Model 2) is statistically significant, suggesting that sociometric status has a stronger impact on LS in the US compared to in Sweden.

Table 4. The relationship between sociometric status and life satisfaction

\begin{tabular}{lcc}
\hline & Model 1 & Model 2 \\
\hline Country (USA=1, Sweden=0) & $0.10^{*}$ & $-0.45^{*}$ \\
Sociometric status & $(0.05)$ & $(0.19)$ \\
& $0.56^{* *}$ & $0.46^{* *}$ \\
Sociometric status X Country & $(0.05)$ & $(0.05)$ \\
& & \\
Constant & & $0.18^{* *}$ \\
& & $(0.06)$ \\
Control variables & $3.67^{* *}$ & $3.95^{* *}$ \\
Observations & $(0.22)$ & $(0.24)$ \\
\hline
\end{tabular}

Notes: ${ }^{*} \mathrm{p}<0.05,{ }^{* *} \mathrm{p}<0.01$. Cell entries represent unstandardized regression coefficients.

Control variables: Age and the Big Five personality traits.

Figure 2. Interaction effect of sociometric status and country on life satisfaction

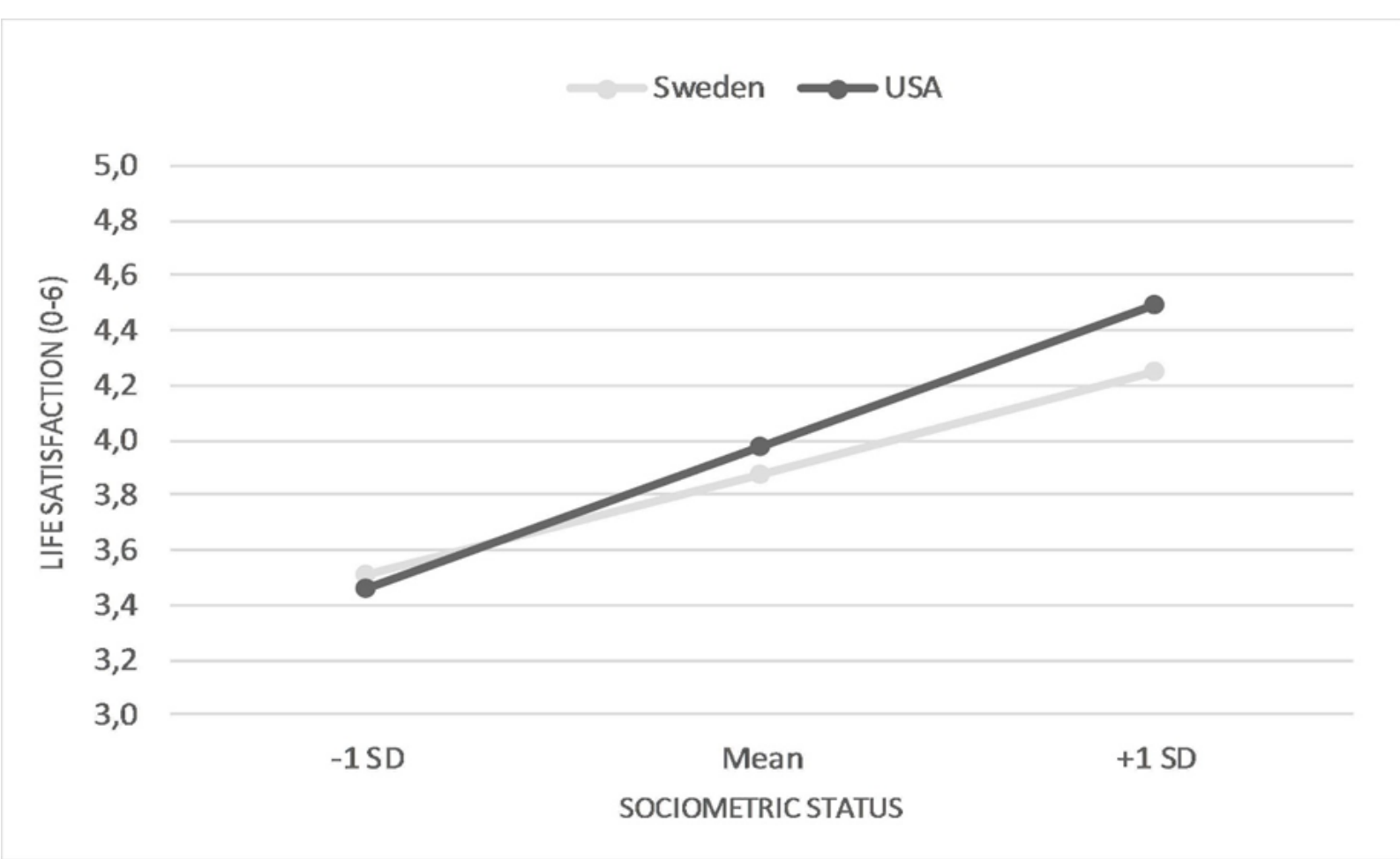

Note: Conditional effects and standard errors: USA: .63 (.043); Sweden: .46 (.049). 
Figure 2 graphically presents the relationship between sociometric status and LS in the two countries. The y-axis represents predicted values on the life satisfaction scale for the mean value of sociometric status and one standard deviation below and above the mean (x-axis). Here we find that the difference in LS between the low- and high-status categories is 1.03 in the US and 0.75 in Sweden. The figure shows that the strength of the relationship between sociometric status and LS is stronger in the US compared to in Sweden.

In summary, the results suggest that both socioeconomic status and sociometric status are more strongly positively related to LS in the US compared to in Sweden. These results provide evidence in support for hypothesis 1A (the relationship between socioeconomic status and LS is stronger in the US compared to in Sweden) and 1B (the relationship between sociometric status and LS is stronger in the US compared to in Sweden).

\subsection{Social status seeking and life satisfaction}

We continue by investigating the relationship between social status seeking and LS. Based on the ambiguous results from previous studies (mainly conducted in the US) that suggest a weak or non-existing relationship between status seeking (low honesty-humility) and LS, we formulated the following hypothesis: social status seeking is negatively associated with LS in Sweden, while (slightly) positively associated with LS in the US.

To test if status seeking has a negative effect on LS in Sweden compared to a slightly positive effect on LS in the US, we examine the effect of status seeking on LS as well as the interaction between status seeking and country in Table 5 below. As previously described, we use the reversed scores on the honesty-humility scale as a proxy for status seeking. As shown in Model 1 , and in line with the correlations presented in Table 2, we do not find a statistically significant relationship between status seeking and LS in the pooled sample. However, the results obtained when including the interaction term between country and status seeking in Model 2 reveal an interesting pattern. The interaction term is statistically significant and shows that the effect of status seeking on LS is clearly very different in the US compared to in Sweden.

In Figure 3 below, we illustrate the impact of social status seeking on LS in the US and Sweden. Similar to previous graphs, the y-axis represents predicted values on the life satisfaction scale for the mean value of status seeking and one standard deviation below and above the mean (x-axis). The graph suggests that status-seeking individuals tend to have slightly higher levels of LS in the US, while status seeking is instead related to lower levels of LS in Sweden. When comparing the low and high categories on the status-seeking scale based on the standard deviation, we find that the difference in LS is 0.25 in the US and -0.46 in Sweden. We note that the negative relationship between status seeking and LS found in Sweden is slightly stronger than the positive relationship found in the US.

In summary, our results showing that status seeking is negatively related to LS in Sweden while slightly positively related in the US provide evidence supporting hypothesis 2 . Moreover, the fact that we find a positive relationship between status seeking and LS in the US reveals that status seeking might not always be detrimental for LS, but in some contexts, such as the American, even slightly positive for individuals' LS. 
Table 5. The relationship between status seeking and life satisfaction

\begin{tabular}{lll}
\hline & Model 1 & Model 2 \\
\hline Country (USA=1, Sweden=0) & $0.26^{* *}$ & $-0.58^{* *}$ \\
& $(0.05)$ & $(0.13)$ \\
Status seeking & 0.00 & $-0.16^{* *}$ \\
& $(0.02)$ & $(0.03)$ \\
Status seeking X Country & & $0.25^{* *}$ \\
& & $(0.04)$ \\
Constant & & 5.47 \\
& 5.09 & $(0.23)$ \\
Control variables & $(0.23)$ & Yes \\
Observations & & 2520 \\
\hline
\end{tabular}

Notes: ${ }^{*} \mathrm{p}<0.05,{ }^{* *} \mathrm{p}<0.01$. Cell entries represent unstandardized regression coefficients.

Control variables: Age and the Big Five personality traits.

Figure 3. Interaction effect of status seeking and country on life satisfaction

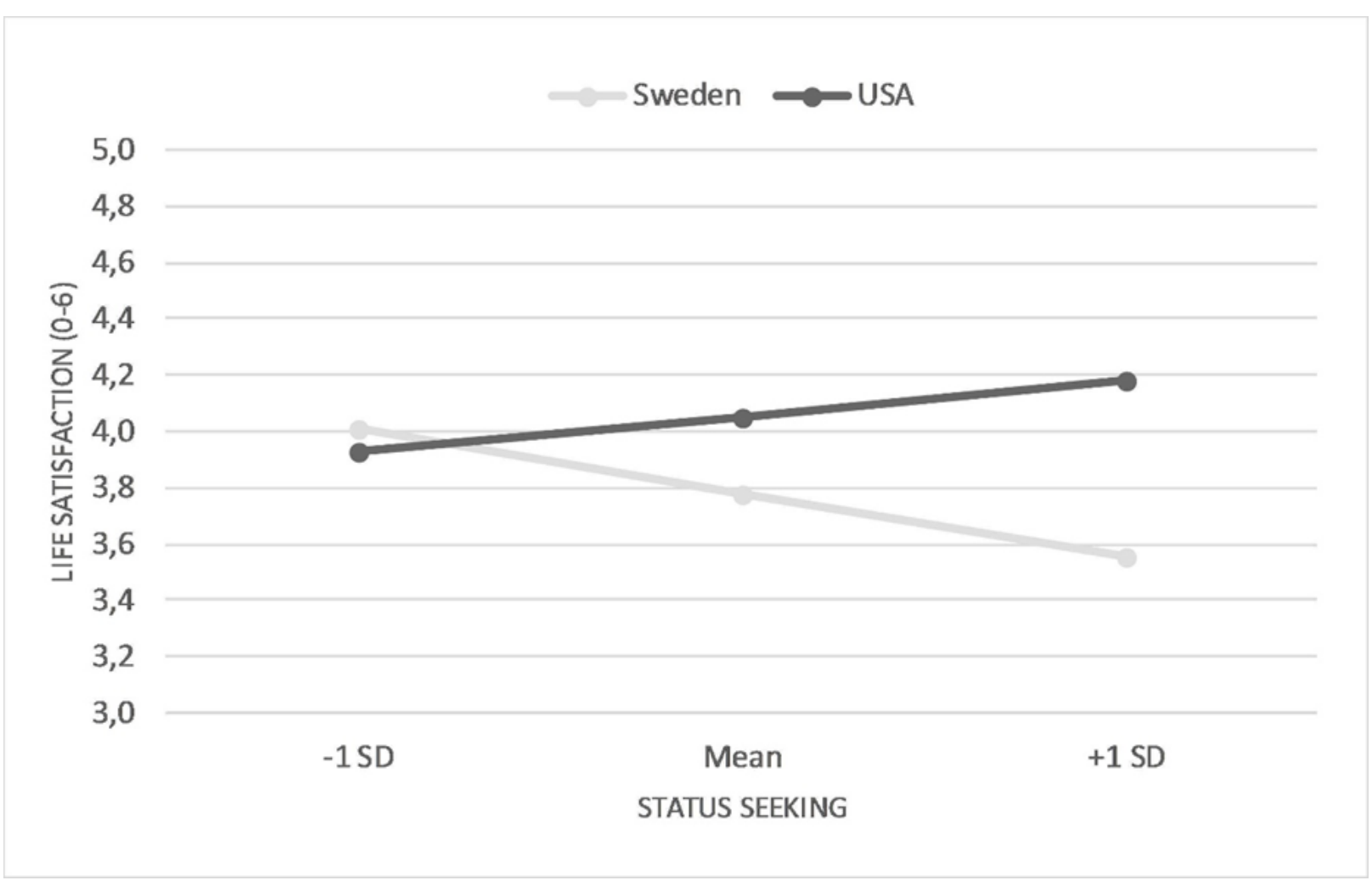

Note: Conditional effects and standard errors: USA: .09 (.024); Sweden: -.16 (.031).

\subsection{Gender differences in the social status-LS relationship}

Finally, we test hypothesis 3 and examine whether there are gender differences in the social status-LS relationship, and whether these potential gender differences are affected by the 
different cultural contexts of the US and Sweden. In Table 6 below, we present three regression models, including socioeconomic status, sociometric status and status seeking, for each country.

Table 6. The interaction effect of gender, social status, and status seeking on life satisfaction

\begin{tabular}{|c|c|c|c|c|c|c|}
\hline \multirow[t]{2}{*}{ Country } & \multicolumn{3}{|c|}{ USA } & \multicolumn{3}{|c|}{ Sweden } \\
\hline & Model 1 & Model 2 & Model 3 & Model 4 & Model 5 & Model 6 \\
\hline \multirow[t]{2}{*}{ Gender $($ Women=1, Men=0) } & $0.36^{*}$ & $0.88^{* *}$ & $0.39^{*}$ & $0.42^{* *}$ & $0.80^{* *}$ & 0.13 \\
\hline & $(0.16)$ & $(0.28)$ & $(0.18)$ & $(0.15)$ & $(0.27)$ & $(0.19)$ \\
\hline \multirow[t]{2}{*}{ Income } & $0.33^{* *}$ & & & $0.19^{* *}$ & & \\
\hline & $(0.04)$ & & & $(0.04)$ & & \\
\hline \multirow[t]{2}{*}{ Income X Gender } & $-0.13^{* *}$ & & & -0.04 & & \\
\hline & $(0.05)$ & & & $(0.05)$ & & \\
\hline \multirow[t]{2}{*}{ Sociometric status } & & $0.76^{* *}$ & & & $0.54^{* * *}$ & \\
\hline & & $(0.06)$ & & & $(0.07)$ & \\
\hline \multirow[t]{2}{*}{ Sociometric status X Gender } & & $-0.26^{* *}$ & & & -0.16 & \\
\hline & & $(0.08)$ & & & $(0.09)$ & \\
\hline \multirow[t]{2}{*}{ Status seeking } & & & $0.13^{* *}$ & & & $-0.15^{* *}$ \\
\hline & & & $(0.04)$ & & & $(0.04)$ \\
\hline \multirow[t]{2}{*}{ Status seeking X Gender } & & & $-0.13^{*}$ & & & 0.02 \\
\hline & & & $(0.05)$ & & & $(0.06)$ \\
\hline \multirow[t]{2}{*}{ Constant } & $4.10^{* *}$ & $3.05^{* *}$ & $4.74^{* *}$ & $4.25^{* *}$ & $3.46^{* *}$ & $5.20^{* *}$ \\
\hline & $(0.33)$ & $(0.36)$ & $(0.36)$ & $(0.29)$ & $(0.33)$ & $(0.31)$ \\
\hline Control variables & Yes & Yes & Yes & Yes & Yes & Yes \\
\hline Observations & 1260 & 1260 & 1260 & 1260 & 1260 & 1260 \\
\hline
\end{tabular}

Notes: ${ }^{*} \mathrm{p}<0.05,{ }^{* *} \mathrm{p}<0.01$. Cell entries represent unstandardized regression coefficients.

Control variables: Age and the Big Five personality traits.

Overall, the results presented in Table 6 show that there are substantial differences between Sweden and the US in the extent to which social status attainment and status seeking affect LS differently among men and women. In the US, we find that the impact of socioeconomic status, sociometric status, and status seeking have a stronger, statistically significant impact on LS among men compared to among women (Models 1-3). However, in Sweden we do not find any statistically significant differences in the relationship between social status attainment, status seeking, and LS between men and women (Models 4-6). Nevertheless, even if we fail to find any statistically significant gender differences in Sweden, it is important to note that the pattern found in the US suggesting that social status is of more importance for LS among men is also found at the trend level regarding socioeconomic status and sociometric status in Sweden. However, regarding status seeking, we do not find this trend, since there is a slightly more pronounced negative effect on LS among men than among women in Sweden. Overall, these differences in the gendered patterns of the relationship between social status and LS provide support for hypothesis 3. We present these findings graphically in Figures 4a-c. 
Figure 4a. Interaction effect of socioeconomic status, country, and gender on life satisfaction
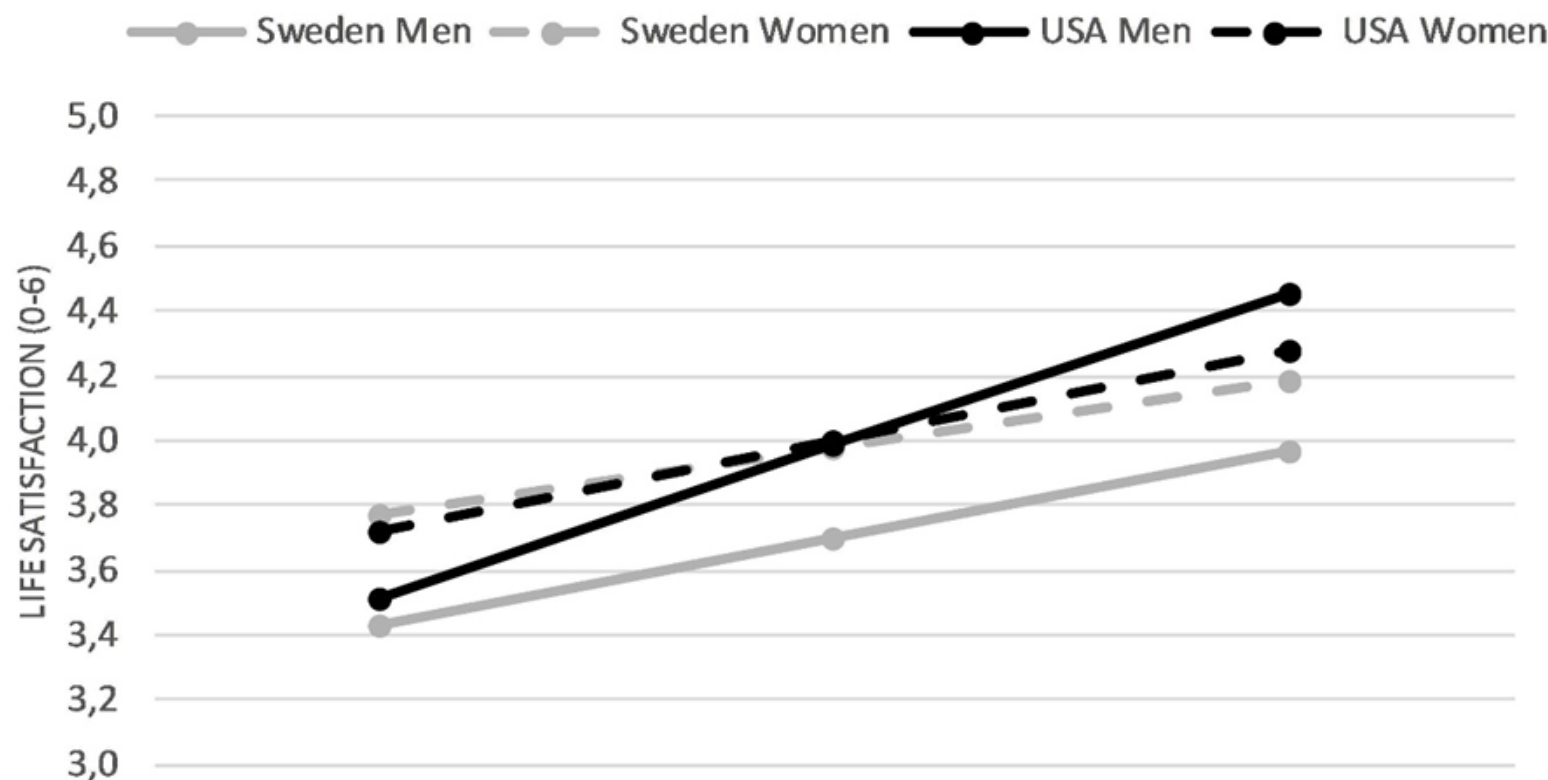

$$
-1 S D
$$

Mean

+1 SD

SOCIOECONOMIC STATUS (INCOME)

Note: Conditional effects and standard errors: USA Men: .35 (.035); USA Women: .21 (.032);

Sweden Men: .20 (.040); Sweden Women: .15 (.040).

Figure $4 \mathrm{~b}$. Interaction effect of sociometric status, country, and gender on life satisfaction
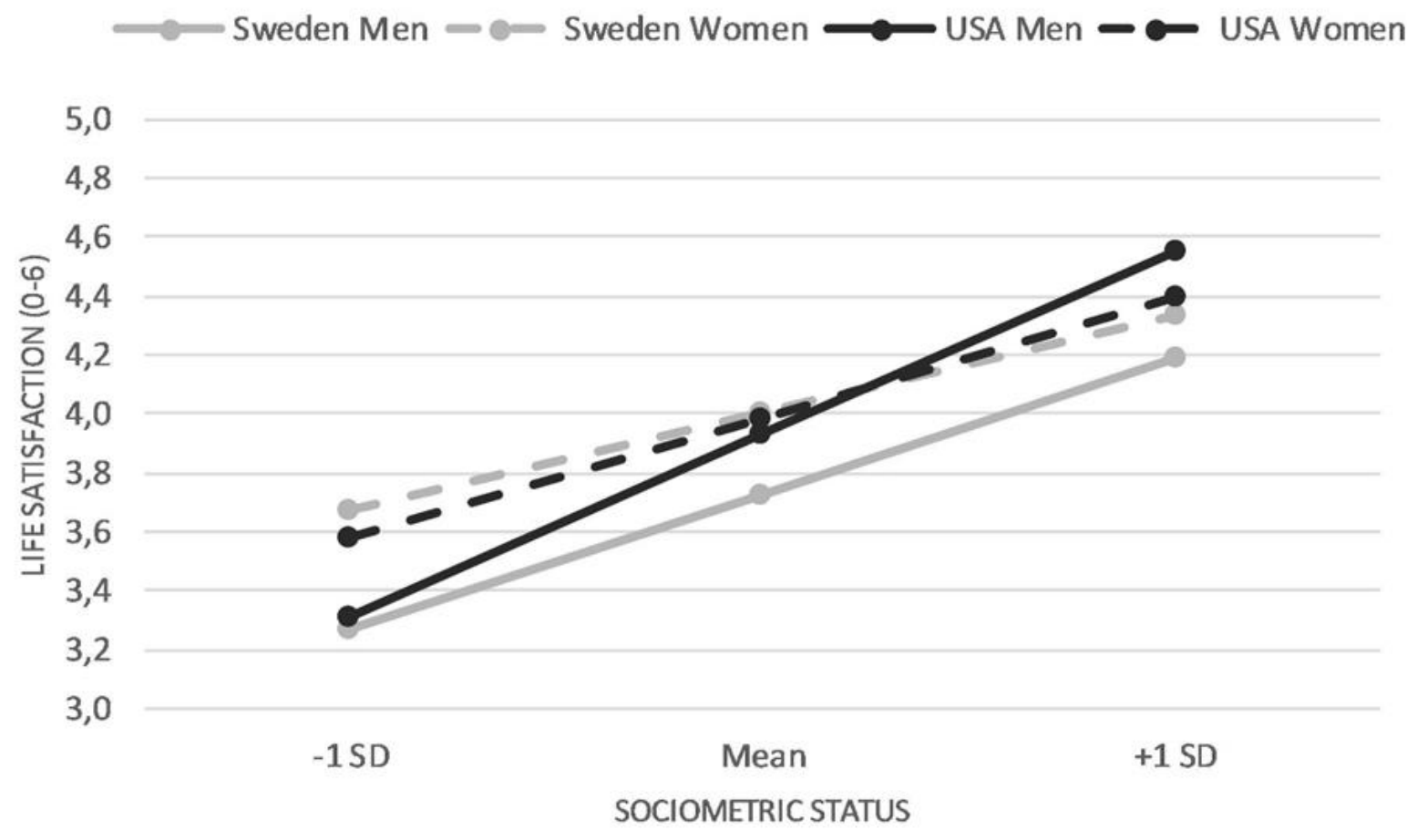

Note: Conditional effects and standard errors: USA Men: .76 (.056); USA Women: .50 (.059);

Sweden Men: .56 (.069); Sweden Women: .40 (.064). 
Figure 4c. Interaction effect of status seeking, country and gender on life satisfaction

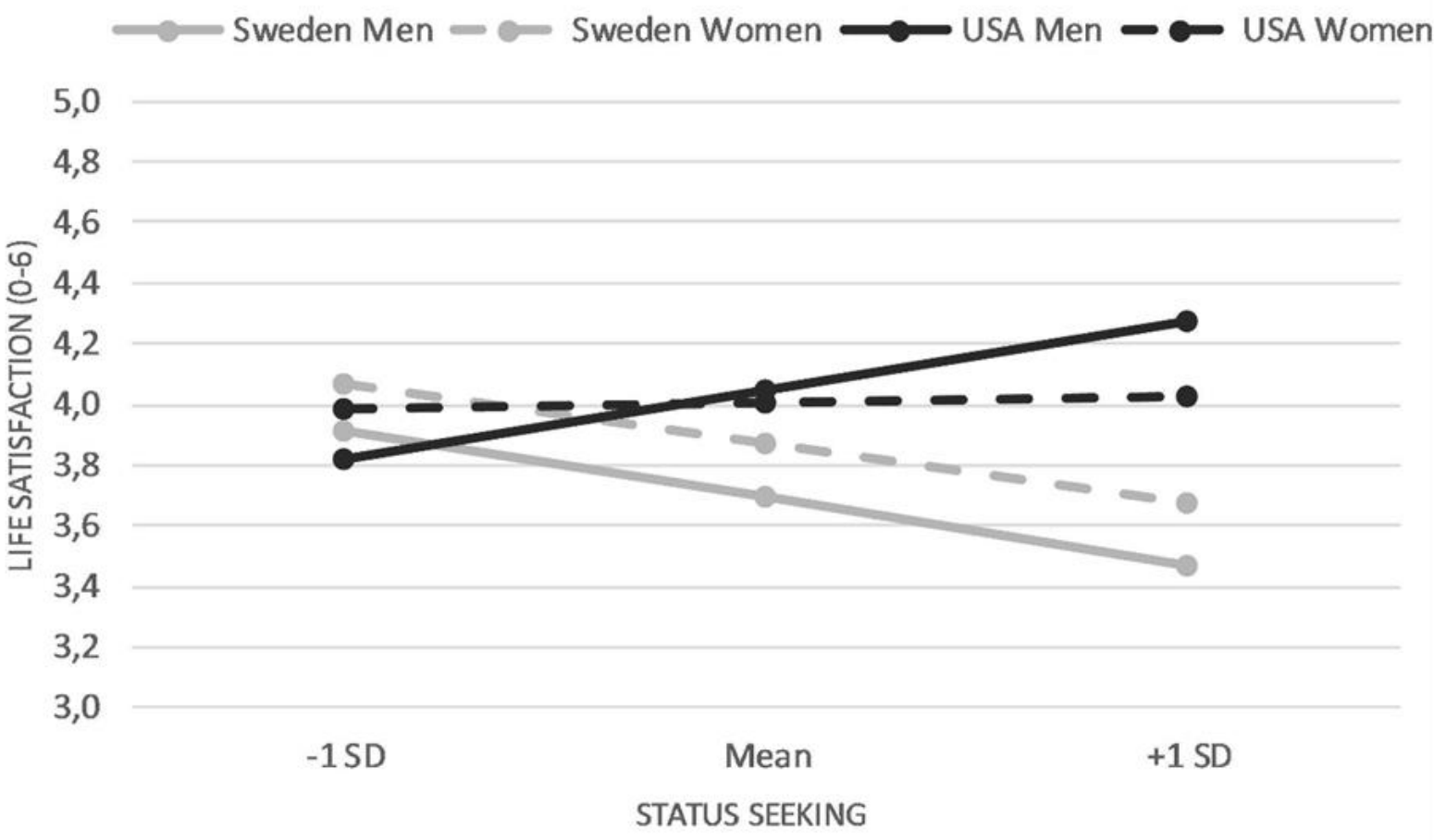

Note: Conditional effects and standard errors: USA Men: .16 (.033);

USA Women: .02 (.033); Sweden Men: .-16 (.043); Sweden Women: -.14 (.043).

\section{Discussion}

The purpose of this study was to examine the influence of cultural context on the relationships between social status attainment, social status seeking and life satisfaction. We examined these relationships in the US and Sweden, two diverse cultural contexts with different societal norms and ideals influencing the importance of social status in society. By focusing on two different aspects of social status attainment, we found that high levels of social status are more beneficial for LS in the US compared to in Sweden. First, income, a common indicator of socioeconomic status, is more strongly connected to LS in the US compared to in Sweden. Second, sociometric status, i.e., the respect and admiration individuals obtain in everyday life, is also a stronger predictor of LS in the US compared to in Sweden. The fact that social status is more important for LS in the US became even more salient when we examined the relationship between social status seeking and LS. In the egalitarian culture of Sweden, where there is an expectation that people should be modest and not view themselves as better than others, the association between status seeking and LS is negative. In contrast, in the hierarchical culture of the US, characterized by competition and assertiveness, status seeking is associated with higher levels of LS.

Regarding potential gender differences in the relationship between social status and LS, we find that such differences are generally more salient in the US compared to in Sweden, in line with our expectations based on the theories about differences in cultural orientations relating to masculinity, mastery and hierarchy (Hofstede, 2001; Schwartz, 2006). An illustrative example of how status seeking among men appears to be accepted and even rewarded in the US is the case of Donald Trump, who scores extremely low on honesty-humility, according to a recent study of his public persona (Visser, Book, \& Volk, 2017). This suggests that, for a large proportion of the American citizenry, high levels of status seeking are clearly accepted, even for the head of state. 
By showing that the effects of both social status attainment and status seeking are more strongly associated with LS in the US compared to in Sweden, our study provides novel insights regarding the role of culture as moderating the relationship between social status and LS. Therefore, the study also contributes to the broader field, focusing on the role of cultural context in influencing the strength and direction of the relationships between different determinants and LS. Further, because previous comparative research on this topic is limited to contrasting Asian and American contexts, our results are particularly interesting, as they suggest that cultural values and ideals can influence the determinants of LS in countries within the Western world.

It is important to note that although we have found that cultural differences between the US and Sweden seem to be of importance in moderating the strength of the relationship between social status and LS, social status attainment is still positively associated with LS, even in the relatively egalitarian context of Sweden where modesty and humility are important ideals. This finding is, however, not that surprising, since it is hard to imagine a society where high social status (particularly sociometric status) would not be beneficial for LS. Indeed, previous research suggests that social status is fundamentally rewarding and even predicts wellbeing among other animals such as chimpanzees (Weiss, King, \& Enns, 2002).

A potential limitation with our study might be the fact that we used data derived from a websurvey panel rather than from random samples representative of the populations in the US and Sweden. However, previous studies have shown that web-survey panels similar to the panels used in this study tend to be representative of the general population (Heen et al., 2014; see also Clifford, Jewell, \& Waggoner, 2015). Another limitation is that we used a cross-sectional correlational research design, which allows for other interpretations of the observed associations. For instance, LS might affect social status attainment rather than the other way round. We certainly do not rule out the possibility that LS might influence social status attainment, since previous research has shown that LS is a desirable trait leading to increased social acceptance and liking (Lyubomirsky, King, \& Diener, 2005). However, other research has also shown that social status predicts LS even when using longitudinal and experimental research designs, suggesting that social status indeed affects LS (Anderson et al., 2012). More importantly, it is not clear how to theoretically interpret the main results reported in this paper (that both social status attainment and status seeking are more strongly associated with LS in the US compared to in Sweden), if the causation between social status and LS is reversed. It is important for future research to investigate whether the findings observed in this study hold when using longitudinal and experimental study designs that provide better means for testing causality.

Further, some potential limitations might apply to our measures of social status. For instance, one can claim that our measure of socioeconomic status (income) not only measures an individual's status position in society at large, but also to some extent measures the fulfillment of basic material needs. Income might play a more important role for need fulfillment in the US compared to in Sweden, due to the universal and encompassing nature of the Swedish welfare state (Korpi, 2000). Country differences in basic needs fulfillment rather than cultural differences in the importance of social status could potentially explain the interaction effect found between country and socioeconomic status on LS. However, we see this as unlikely because the differences in LS between income groups across all income categories were larger in the US compared to in Sweden, not just among the lower income groups. More importantly, even when controlling for the respondents' satisfaction with their financial situation (see Model 3 in Table 4), we still found that socioeconomic status was more strongly associated with LS in the US compared to in Sweden. 
We also need to discuss our measure of sociometric status because it is not framed in relation to specific reference groups in the respondents' local environment (e.g., perceived status among co-workers, friends etc.). In principle, respondents could therefore think of their status position in society at large as their frame of reference, instead of their status position in the local environment. However, we see this as unlikely for two reasons. First, the overlap between our measure of sociometric status and income (measuring status in society at large) was modest $(\mathrm{r}=$ 0.39). Second, our measure of sociometric status had a stronger relationship with LS than socioeconomic status, replicating previous studies which have found that sociometric status is a stronger predictor of LS than socioeconomic status (Anderson et al., 2012).

We see several avenues for future research. Studies should explore why social status has a stronger association with LS in the US compared to in Sweden. For instance, could it be that individuals with high social status tend to have larger and stronger social networks in the US compared to in Sweden? If so, this could help explain the stronger relationship between social status and LS in the US. Indeed, previous research suggests that social status increases individuals' sense of belonging and interpersonal connection. Given the particular importance of social status in the American culture, it can therefore be assumed that this kind of mediation might exist to a greater extent in the US compared to in Sweden. Future research should also investigate if other dimensions of socioeconomic status, such as occupational prestige, display similar country differences regarding the impact on LS. Another interesting question is whether the extent to which individuals have a status-seeking personality changes the effect of social status attainment on LS. This assumption is certainly reasonable in light of the mean value of our status-seeking measure, which suggests that levels of status seeking generally seem to be higher in the US.

Finally, one can also speculate whether the stronger relationship between social status and life satisfaction found in the US is beneficial for societal levels of subjective wellbeing. This is, of course, a complex question, but we argue that the comparably stronger relationship between social status and LS in the US might have a downside. In contrast to many other determinants of LS, social status constitutes a positional good (Layard, 2005). Viewed as a zero-sum game, one person's increase in social status will, by definition, lead to a decrease in social status for another person. This means that it is hard to raise aggregate levels of subjective wellbeing in a society by means of encouraging status-seeking behaviors. Instead, promoting factors that increase life satisfaction, but to a lesser extent constitute positional goods, would be more fruitful alternatives for increasing wellbeing among broader segments in society. Such factors could include harmonious relationships, meaningful work, physical exercise, and social trust (Layard, 2005; Lyubomirsky, 2008). Our study therefore also contributes to the ongoing discussion among policy-makers and scholars who increasingly have come to focus on life satisfaction as a key outcome complementing standard economic measures of human welfare.

\section{Acknowledgments}

We would like to thank the three anonymous reviewers and the editor Gavin R. Slemp for their valuable comments. We also thank Maureen Eger and our colleagues at the Department of Sociology, Umeå University, for valuable comments on previous drafts. The data collection for the data used in this paper was funded by the Swedish Research Council, grant number 2012-1117, "The co-production of social science and society: The case of Happiness studies."

\section{Authors}

Filip Fors Connolly 
Umeå University

filip.fors@umu.se

Ingemar Johansson Sevä

Umeå University

\section{Publishing Timeline}

Received 16 January 2018

Accepted 27 August 2018

Published 9 December 2018

\section{References}

Adler, N. E., Boyce, T., Chesney, M. A., Cohen, S., Folkman, S., Kahn, R. L., \& Syme, S. L. (1994). Socioeconomic status and health: The challenge of the gradient. American Psychologist, 49(1), 15-24. https://doi.org/10.1037/0003-066X.49.1.15

Alesina, A. F., \& Angeletos, G. M. (2003). Fairness and redistribution: US versus Europe (Harvard Institute Research Working Paper No. 1983; MIT Department of Economics Working Paper No. 02-37). https://doi.org/10.2139/ssrn.346545

Anderson, C., Hildreth, J. A. D., \& Howland, L. (2015). Is the desire for status a fundamental human motive? A review of the empirical literature. Psychological Bulletin, 141(3), 574-601. https://doi.org/10.1037/a0038781

Anderson, C., Kraus, M. W., Galinsky, A. D., \& Keltner, D. (2012). The local-ladder effect: Social status and subjective well-being. Psychological Science, 23(7), 764-771. https://doi.org/10.1177/0956797611434537

Argyle, M. (2003). Causes and correlates of happiness. In D. Kahneman, E. Diener, \& N. Schwarz (Eds.), Well-being: The foundations of hedonic psychology (pp. 353-373). New York, NY: Russell Sage Foundation.

Blanchflower, D. G. (2009). International evidence on well-being. In A. B. Krueger (Ed.) Measuring the subjective well-being of nations: National Accounts of time use and well-being (pp. 155-226). Chicago, IL: University of Chicago Press. https://doi.org/10.7208/chicago/9780226454573.003.0008

Blanchflower, D. G., \& Oswald, A. J. (2008). Is well-being U-shaped over the life cycle? Social Science \& Medicine, 66(8), 1733-1749. https://doi.org/10.1016/j.socscimed.2008.01.030

Brülde, B. (2007). Happiness theories of the good life. Journal of Happiness Studies, 8(1), 15-49. https://doi.org/10.1007/s10902-006-9003-8

Buss, D. M. (1999). Human nature and individual differences: The evolution of human personality. In L. A. Pervin \& O. P. John (Eds.), Handbook of personality: Theory and research (2nd ed.), pp. 31-56. New York, NY: Guilford Press.

Cheung, F., \& Lucas, R. E. (2014). Assessing the validity of single-item life satisfaction measures: Results from three large samples. Quality of Life Research, 23(10), 2809-2818. https://doi.org/10.1007/s11136$\underline{014-0726-4}$

Clifford, S., Jewell, R. M., \& Waggoner, P. D. (2015). Are samples drawn from Mechanical Turk valid for research on political ideology? Research \& Politics, 2(4), 1-9. https://doi.org/10.1177/2053168015622072

Costa, P. T., Jr., \& McCrae, R. R. (1990). Personality disorders and the five-factor model of personality. Journal of Personality Disorders, 4(4), 362-371. https://doi.org/10.1521/pedi.1990.4.4.362

Diener, E. (1984). Subjective well-being. Psychological Bulletin, 95(3), 542-575. https://doi.org/10.1037/00332909.95.3.542

Dolan, P., Peasgood, T., \& White, M. (2008). Do we really know what makes us happy? A review of the economic literature on the factors associated with subjective well-being. Journal of Economic Psychology, 29(1), 94-122. https://doi.org/10.1016/j.joep.2007.09.001 
Doorslaer, E., Wagstaff, A., Bleichrodt, H., Calonge, S., Gerdtham, U. G., Gerfin, M., . . \& \& Winkelhake, O. (1997). Income-related inequalities in health: Some international comparisons. Journal of Health Economics, 16(1), 93-112. https://doi.org/10.1016/S0167-6296(96)00532-2

Fors, F., \& Kulin, J. (2016). Bringing affect back in: Measuring and comparing subjective well-being across countries. Social Indicators Research, 127(1), 323-339. https://doi.org/10.1007/s11205-015-0947-0

Fritzell, J. (1999). Incorporating gender inequality into income distribution research. International Journal of Social Welfare, 8(1), 56-66. https://doi.org/10.1111/1468-2397.00062

Fujishiro, K., Xu, J., \& Gong, F. (2010). What does “occupation" represent as an indicator of socioeconomic status? Exploring occupational prestige and health. Social Science \& Medicine, 71(12), 2100-2107. https://doi.org/10.1016/j.socscimed.2010.09.026

Hayes, A. F. (2013). Introduction to mediation, moderation and conditional process analysis. New York, NY: Guilford Press.

Hays, N. A. (2013). Fear and loving in social hierarchy: Sex differences in preferences for power versus status. Journal of Experimental Social Psychology, 49(6), 1130-1136. https://doi.org/10.1016/j.jesp.2013.08.007

Heen, M. S., Lieberman, J. D., \& Miethe, T. D. (2014). A comparison of different online sampling approaches for generating national samples. Center for Crime and Justice Policy.

Helliwell, J. F., Huang, H., \& Wang, S. (2017). The social foundations of world happiness. World Happiness Report 2017, 8.

Hofstede, G. (1980). Motivation, leadership, and organization: Do American theories apply abroad? Organizational Dynamics, 9(1), 42-63. https://doi.org/10.1016/0090-2616(80)90013-3

Hofstede, G. (2001). Culture's consequences: Comparing values, behaviors, institutions, and organizations across cultures. Thousand Oaks, CA: Sage.

Hogan, R., \& Hogan, J. (1991). Personality and status. In D. G. Gilbert \& J. J. Connolly (Eds.), Personality, Social Skills, and Psychopathology. Perspectives on Individual Differences (pp. 137-154). Boston, MA: Springer. https://doi.org/10.1007/978-1-4899-0635-9 6

Joo, S-H., \& Grable, J. E. (2004). An exploratory framework of the determinants of financial satisfaction. Journal of Family and Economic Issues, 25(1), 25-50. https://doi.org/10.1023/B:JEEI.0000016722.37994.9f

Kahneman, D., \& Deaton, A. (2010). High income improves evaluation of life but not emotional wellbeing. Proceedings of the National Academy of Sciences, 107(38), 16489-16493. https://doi.org/10.1073/pnas.1011492107

Kajonius, P. J., \& Dåderman, A. M. (2014). Exploring the relationship between honesty-humility, the big five, and liberal values in Swedish students. Europe's Journal of Psychology, 10(1), 104-117. https://doi.org/10.5964/ejop.v10i1.672

Kasser, T., \& Ryan, R. M. (1993). A dark side of the American dream: Correlates of financial success as a central life aspiration. Journal of Personality and Social Psychology, 65(2), 410-422. https://doi.org/10.1037/0022-3514.65.2.410

Korpi, W. (2000). Faces of inequality: Gender, class, and patterns of inequalities in different types of welfare states. Social Politics: International Studies in Gender, State \& Society, 7(2), 127-191. https://doi.org/10.1093/sp/7.2.127

Kwan, V. S. Y., Bond, M. H., \& Singelis, T. M. (1997). Pancultural explanations for life satisfaction: Adding relationship harmony to self-esteem. Journal of Personality and Social Psychology, 73(5), 10381051. https://doi.org/10.1037/0022-3514.73.5.1038

Layard, R. (2005). Happiness: Lessons from a New Science. London, England: Penguin Books.

Layard, R., Clark, A. E., Cornaglia, F., Powdthavee, N., \& Vernoit, J. (2014). What predicts a successful life? A life-course model of well-being. The Economic Journal, 124(580), F720-F738.

https://doi.org/10.1111/ecoj.12170

Lee, K., \& Ashton, M. C. (2004). Psychometric properties of the HEXACO personality inventory. Multivariate Behavioral Research, 39(2), 329-358. https://doi.org/10.1207/s15327906mbr3902 8

Lee, K., \& Ashton, M. C. (2013). The H factor of personality: Why some people are manipulative, self-entitled, materialistic, and exploitive - and why it matters for everyone. Waterloo, Ontario: Wilfrid Laurier. 
Lee, K., Ashton, M. C., Ogunfowora, B., Bourdage, J. S., \& Shin, K-H. (2010). The personality bases of socio-political attitudes: The role of honesty-humility and openness to experience. Journal of Research in Personality, 44(1), 115-119. https://doi.org/10.1016/j.jrp.2009.08.007

Lyubomirsky, S. (2008). The how of happiness: A scientific approach to getting the life you want. New York, NY: Penguin Press.

Lyubomirsky, S., King, L., \& Diener, E. (2005). The benefits of frequent positive affect: Does happiness lead to success? Psychological Bulletin, 131(6), 803-855. https://doi.org/10.1037/0033-2909.131.6.803

Mellor, D., Stokes, M., Firth, L., Hayashi, Y., \& Cummins, R. (2008). Need for belonging, relationship satisfaction, loneliness, and life satisfaction. Personality and Individual Differences, 45(3), 213-218. https://doi.org/10.1016/j.paid.2008.03.020

Minkov, M., \& Hofstede, G. (2012). Is national culture a meaningful concept? Cultural values delineate homogeneous national clusters of in-country regions. Cross-Cultural Research, 46(2), 133-159. https://doi.org/10.1177/1069397111427262

OECD (2011). How's life? Measuring well-being. OECD. https://doi.org/10.1787/9789264121164-en

Ohanian, L. E., \& Raffo, A. (2012). Aggregate hours worked in OECD countries: New measurement and implications for business cycles. Journal of Monetary Economics, 59(1), 40-56.

https://doi.org/10.1016/j.jmoneco.2011.11.005

Oishi, S., Diener, E. F., Lucas, R. E., \& Suh, E. M. (1999). Cross-cultural variations in predictors of life satisfaction: Perspectives from needs and values. Personality and Social Psychology Bulletin, 25(8), 980990. https://doi.org/10.1177/01461672992511006

Okulicz-Kozaryn, A. (2011). Europeans work to live and Americans live to work (who is happy to work more: Americans or Europeans?). Journal of Happiness Studies, 12(2), 225-243. https://doi.org/10.1007/s10902-010-9188-8

Pollock, N. C., Noser, A. E., Holden, C. J., \& Zeigler-Hill, V. (2016). Do orientations to happiness mediate the associations between personality traits and subjective well-being? Journal of Happiness Studies, 17(2), 713-729. https://doi.org/10.1007/s10902-015-9617-9

Sacks, D. W., Stevenson, B., \& Wolfers, J. (2012). The new stylized facts about income and subjective wellbeing. Emotion, 12(6), 1181 -1187. https://doi.org/10.1037/a0029873

Schwartz, S. H. (1994). Are there universal aspects in the structure and contents of human values? Journal of Social Issues, 50(4), 19-45. https://doi.org/10.1111/j.1540-4560.1994.tb01196.x

Schwartz, S. H. (2006). A theory of cultural value orientations: Explication and applications. Comparative Sociology, 5(2), 137-182. https://doi.org/10.1163/156913306778667357

Sibley, C. G., Luyten, N., Purnomo, M., Mobberley, A., Wootton, L. W., Hammond, M. D., . . \& \& McLellan, L. (2011). The Mini-IPIP6: Validation and extension of a short measure of the Big-Six factors of personality in New Zealand. New Zealand Journal of Psychology, 40(3), 142-159.

Smith, J. P. (2004). Unraveling the SES: Health connection. The Institute for Fiscal Studies. https://doi.org/10.1920/wp.ifs.2004.0402

Steel, P., Schmidt, J., \& Shultz, J. (2008). Refining the relationship between personality and subjective well-being. Psychological Bulletin, 134(1), 138-161. https://doi.org/10.1037/0033-2909.134.1.138

Svallfors, S. (2006). The moral economy of class: Class and attitudes in comparative perspective. Stanford, CA: Stanford University Press.

Treiman, D. J. (2013). Occupational prestige in comparative perspective. Amsterdam, the Netherlands: Elsevier.

Veenhoven, R. (2015). Social conditions for human happiness: A review of research. International Journal of Psychology, 50(5), 379-391. https://doi.org/10.1002/ijop.12161

Visser, B. A., Book, A. S., \& Volk, A. A. (2017). Is Hillary dishonest and Donald narcissistic? A HEXACO analysis of the presidential candidates' public personas. Personality and Individual Differences, 106(1), 281-286. https://doi.org/10.1016/j.paid.2016.10.053

Weaver, C. N. (1977). Occupational prestige as a factor in the net relationship between occupation and job satisfaction. Personnel Psychology, 30(4), 607-612. https://doi.org/10.1111/j.1744-6570.1977.tb02330.x 
Weiss, A., King, J. E., \& Enns, R. M. (2002). Subjective well-being is heritable and genetically correlated with dominance in chimpanzees (Pan troglodytes). Journal of Personality and Social Psychology, 83(5), 1141-1149. https://doi.org/10.1037/0022-3514.83.5.1141 


\begin{tabular}{|c|c|c|c|c|c|c|c|c|c|c|c|}
\hline \multicolumn{12}{|c|}{ Appendix. Table 1. Bivariate correlations (Pearson's R) } \\
\hline & Income & $\begin{array}{l}\text { Socio- } \\
\text { metric } \\
\text { status }\end{array}$ & $\begin{array}{l}\text { Status } \\
\text { seeking }\end{array}$ & Age & Gender & Extraversion & Agreeableness & Conscientiousness & Neuroticism & Openness & $\begin{array}{l}\text { Financial } \\
\text { satisfaction }\end{array}$ \\
\hline Life satisfaction & $0.32^{* *}$ & $0.47^{* *}$ & 0.01 & $0.05^{*}$ & $-0.06^{* *}$ & $0.32^{* *}$ & $0.11^{* *}$ & $0.15^{* *}$ & $-0.47^{* *}$ & $0.10^{* *}$ & $0.60^{* *}$ \\
\hline Income & & $0.39^{* *}$ & $0.21^{* *}$ & $-0.09^{* *}$ & $-0.17^{* *}$ & $0.25^{* *}$ & -0.01 & $0.05^{*}$ & $-0.11^{* *}$ & 0.00 & $0.49^{* *}$ \\
\hline Sociometric status & & & $0.31^{* *}$ & $-0.10^{* *}$ & $-0.14^{* *}$ & $0.50^{* *}$ & $0.18^{* *}$ & $0.15^{* *}$ & -0.26 & $0.16^{* *}$ & $0.47^{* *}$ \\
\hline Status seeking & & & & $-0.37^{* *}$ & $-0.20^{* *}$ & $0.22^{* *}$ & $-0.18^{* *}$ & $-0.14^{* *}$ & $0.20^{* *}$ & $-0.09 * *$ & $0.09^{* *}$ \\
\hline Age & & & & & $-0.05^{*}$ & -0.02 & $0.06^{* *}$ & $0.19^{* *}$ & $-0.31^{* *}$ & 0.00 & 0.02 \\
\hline Gender & & & & & & $-0.05^{*}$ & $0.26^{* *}$ & $0.06^{* *}$ & $0.15^{* *}$ & $0.04^{*}$ & -0.16 \\
\hline Extraversion & & & & & & & $0.29^{* *}$ & $0.10^{* *}$ & $-0.18^{* *}$ & $0.29^{* *}$ & $0.30^{* *}$ \\
\hline Agreeableness & & & & & & & & $0.20^{* *}$ & $-.09^{* *}$ & $0.42^{* *}$ & 0.02 \\
\hline Conscientiousness & & & & & & & & & $-0.26^{* *}$ & $0.17^{* *}$ & $0.14^{* *}$ \\
\hline Neuroticism & & & & & & & & & & $-0.12^{* *}$ & $-0.31^{* *}$ \\
\hline Openness & & & & & & & & & & & 0.02 \\
\hline
\end{tabular}

Notes: ${ }^{*} \mathrm{p}<0.05,{ }^{* *} \mathrm{p}<0.01$. Gender (Man=0, Woman $=1$ ). 